\title{
DISCUSSION
}

\section{Constant rate of strain consolidation of Singapore marine clay}

\author{
K. LEE, V. CHOA, S. H. LEE and S. H. QUEK (1993). Géotechnique 43, No. 3, 471-488
}

\section{S. S. Almeida, I. S. Martins and S. R. L.} Carvalho, Federal University of Rio de Janeiro

Constant rate of strain and incremental loading consolidation tests have been performed in Rio de Janeiro clay. The Rio de Janeiro clay, formed about 6000 years ago in a fluvial-marine environment, shows field vane strengths of $8-20 \mathrm{kPa}$, an average sensitivity $S_{\mathrm{t}}$ of 4.3 mcasured in ficld vanc tests and a liquidity index $I_{\mathrm{L}}$ of just above unity (Ortigão \& Collet, 1987), thus being softer but somewhat similar to Singapore clay. The consolidation behaviour of Rio de Janeiro soft clay has been well studied in laboratory tests, in situ tests and field trials (Lacerda, Costa-Filho, Coutinho \& Duarte, 1977; Almeida \& Ferreira, 1993).

In parallel to the test programme a method has been developed (Carvalho, Almeida \& Martins, 1993; Almeida, Martins \& Carvalho, 1995) to select the rate of strain in CRS tests and to estimate the expected pore pressure ratio $u_{\mathrm{b}} / \sigma_{\mathrm{v}}$. This method is based on a parallelism between the consolidation conditions imposed in incremental and constant rate of strain tests using, respectively, Terzaghi's and Wissa's small strain consolidation theories. The selected rate of displacement used in the CRS test is that measured at a chosen degree of consolidation $U_{\mathrm{c}}$ at a stage of the incremental test (IL). In doing so it can be shown (Carvalho et al., 1993; Almeide et al., 1995) that the pore pressure ratio $u_{\mathrm{b}} / \sigma_{\mathrm{v}}$ can be established in advance. For the conventional incremental test $\left(\Delta \sigma_{\mathrm{v}} / \sigma_{\mathrm{v}}=1\right)$ the governing equation is

$$
\frac{u_{\mathrm{b}}}{\sigma_{\mathrm{v}}}=\frac{2 H_{\mathrm{cr}}}{H_{\mathrm{i} 1}} \exp \left(\frac{-\Pi^{2} T_{\mathrm{c}}}{4}\right)
$$

where $H_{\mathrm{cr}}$ and $H_{\mathrm{il}}$ are the current heights of CRS and incremental specimens, respectively, and $T_{\mathrm{c}}$ is the value of the time factor $T_{\mathrm{v}}$ corresponding to the chosen degree of consolidation $U_{\mathrm{c}}$. From equation (18) it can be concluded that it is possible to perform a CRS test with a predetermined value of $u_{b} / \sigma_{v}$ by choosing a suitable value of $T_{c}$, which is thus the corresponding $U_{\mathrm{c}}$ value. The speed associated with this value of $U_{c}$ is then determined from the settlement-time readings of the IL test stage. Alternatively, a speed at a chosen value of $U$ can be measured in the IL test and used in the CRS test. As $T_{v}$ is a unique function of $U_{\mathrm{c}}$, for each value of $H_{\mathrm{cr}} / H_{\mathrm{il}}$ the graph in Fig. 15 can be plotted.

Equation (18) has been checked by performing a series of CRS and incremental tests on undisturbed specimens of Rio de Janiero soft clay. Values of $u_{\mathrm{b}} / \sigma_{\mathrm{v}}$ measured in CRS tests and computed with equation (18) from incremental tests (in the stress range 100-200 $\mathrm{kPa}$ ) are compared in Table 4. Good estimates of $u_{\mathrm{b}} / \sigma_{\mathrm{v}}$ can be obtained provided $U$ is in the range $80-95 \%$ and the loading stage belongs to the normally consolidated range. The Authors suggest that the $u_{\mathrm{b}} / \sigma_{\mathrm{v}}$ ratio may not be a useful parameter for selecting the test rate. We agree that recommended $u_{\mathrm{b}} / \sigma_{\mathrm{v}}$ ratios should not be generalized irrespective of soil type. However, the good agreement obtained here between predicted $u_{\mathrm{b}} / \sigma_{\mathrm{v}}$ from IL tests and measured $u_{\mathrm{b}} / \sigma_{\mathrm{v}}$ in CRS tests suggests that this ratio can be predicted reliably.

The Authors have recommended that test rates should be selected so that $\beta$ values do not exceed

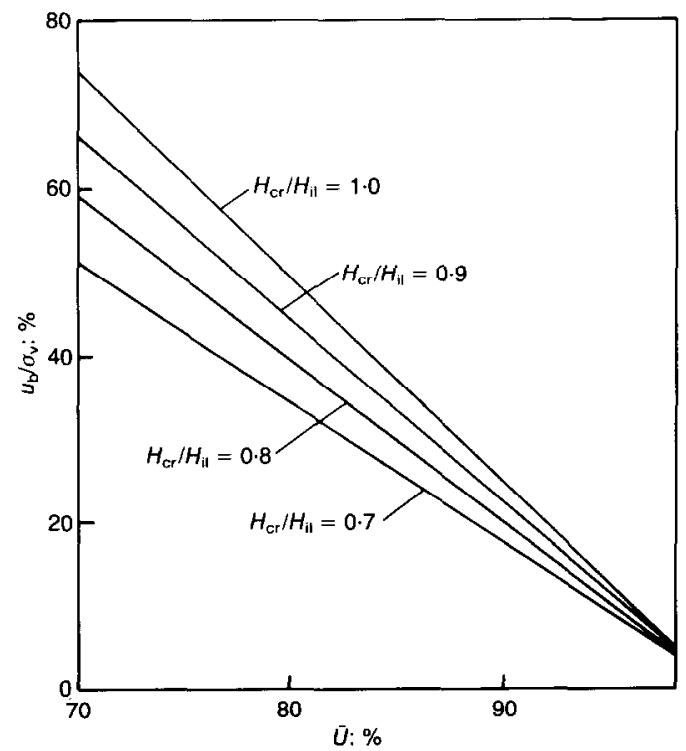

Fig. 15. Relationship between $\bar{U}$ and $u / \sigma_{\mathrm{v}}$ 
Table 4. Computed and measured pore pressure ratio $u_{\mathrm{b}} / \sigma_{\mathrm{v}}$ in Rio de Janeiro soft clay*

\begin{tabular}{|c|c|c|c|c|c|}
\hline $\begin{array}{l}\text { Depth of } \\
\text { specimen } \\
\text { s: m }\end{array}$ & $\begin{array}{l}\text { Measured } u_{\mathrm{b}} / \sigma_{v} \\
\text { in CRS tests }\end{array}$ & $\begin{array}{l}\text { Strain rates: } \\
\qquad \mathbf{s}^{-1}\end{array}$ & $\beta$ values & $\begin{array}{l}\text { Computed } u_{\mathrm{b}} / \sigma_{\mathrm{v}} \\
\text { using } \\
\text { equation }(18)\end{array}$ & $\begin{array}{c}\text { Values of } U \\
\text { in IL } \\
\text { tests: } \%\end{array}$ \\
\hline $3 \cdot 0-3 \cdot 5$ & $\begin{array}{l}0.18 \text { (CRS5) } \\
0.19 \text { (CRS6) }\end{array}$ & $5.3 \times 10^{-6}$ & $0 \cdot 15$ & $\begin{array}{l}0 \cdot 22 \text { (IL2) } \\
0 \cdot 22 \text { (IL3) } \\
0 \cdot 18 \text { (IL4) }\end{array}$ & $\begin{array}{l}81 \\
80 \\
84\end{array}$ \\
\hline $5 \cdot 0-5 \cdot 5$ & 0.20 (CRS7) & $5 \cdot 3 \times 10^{-6}$ & $0 \cdot 15$ & $\begin{array}{l}0 \cdot 16 \text { (IL5) } \\
0 \cdot 15 \text { (IL6) }\end{array}$ & $\begin{array}{l}91 \\
91\end{array}$ \\
\hline $5 \cdot 0-5 \cdot 5$ & $0 \cdot 10$ (CRS8) & $2.0 \times 10^{-6}$ & 0.06 & $\dagger$ & $>95$ \\
\hline $5 \cdot 0-5 \cdot 5$ & 0.31 (CRS9) & $1.0 \times 10^{-5}$ & $0 \cdot 28$ & $\begin{array}{l}0 \cdot 37 \text { (IL5) } \\
0 \cdot 36 \text { (IL6) }\end{array}$ & $\begin{array}{l}78 \\
79\end{array}$ \\
\hline
\end{tabular}

* Test designation is shown in brackets.

† Equation (18) not applicable as $U_{\mathrm{c}}$ is greater than $95 \%$ (secondary compression is significant).

$0 \cdot 10$ (and $u_{\mathrm{b}} / \sigma_{\mathrm{v}}$ is lower than $0 \cdot 15$ ). Values of $\beta$ for the normally consolidated condition of the five CRS tests (with $c_{\mathrm{v}}=1.3 \times 10^{-8} \mathrm{~m}^{2} / \mathrm{s}$ for all tests) performed in the present test programme are shown in Table 4. The slowest test CRS8 produced $\beta=0.06$ below the upper limit $(\beta=0.10)$ proposed by the Authors. However, the remaining four tests produced $\beta$ greater than $0 \cdot 10$, which is outside the range suggested by the Authors. Compression curves and $c_{v}$ data for CRS tests (with about 200 data points for each test) and incremental tests (end of primary condition) are compared in Figs 16 and 17. The good agreement obtained suggests that CRS tests (interpreted with
Wissa's small strain theory) are satisfactory. Therefore $\beta$ values of larger than $0 \cdot 1$, and thus also values of $u_{\mathrm{b}} / \sigma_{\mathrm{v}}$ larger than 0.15 , are acceptable for Rio de Janeiro soft clay. The minimum suggested value of $u_{\mathrm{b}} / \sigma_{\mathrm{v}}$ according to our interpretation method is $0 \cdot 10$, which corresponds roughly to $U_{\mathrm{c}}=95 \%$. At larger $U$ values (and smaller pore pressure ratios) the secondary consolidation is of greater significance. Thus one can expect a deviation between measured and computed values with equation (18), which does not account for secondary consolidation. This is why $u_{\mathrm{b}} / \sigma_{\mathrm{v}}$ could not be computed for test CRS8 (see Table 4).

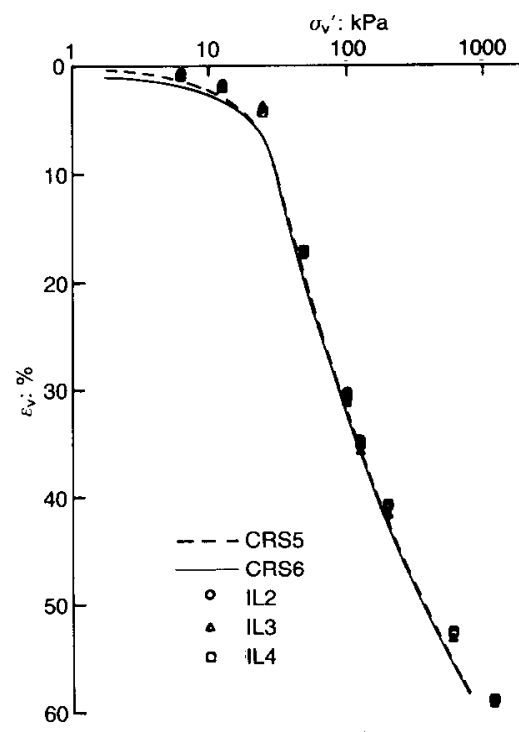

(a)

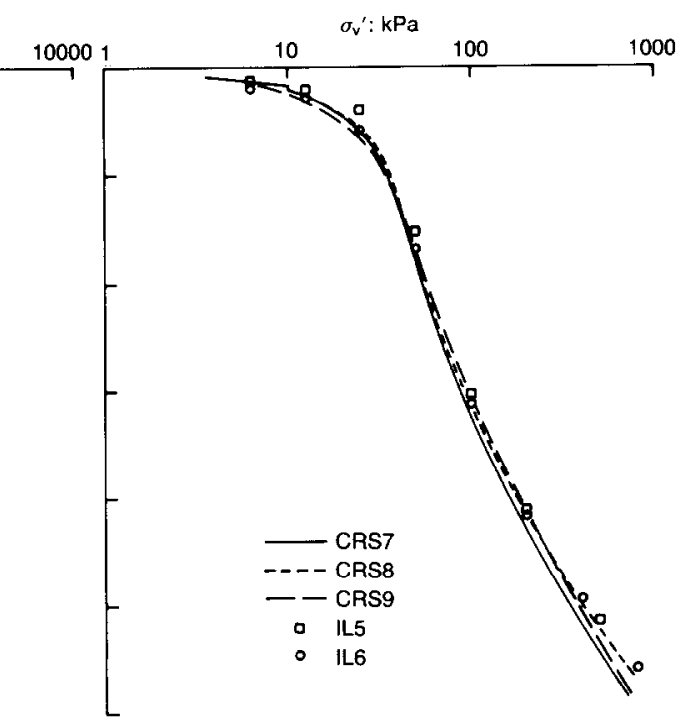

(b)

Fig. 16. Vertical strain plotted against effective stress data for CRS and incremental tests in Rio de Janeiro soft clay: (a) depth 30-3.5 m; (b) depth 5.0-5.5 m 


\section{Authors' reply}

Three issues have been raised: the use of a pore pressure ratio exceeding $0 \cdot 15$, alternative methods of selecting test rate, and the effect of secondary consolidation on the results of slow tests. As the theory on which the Paper was based did not consider secondary consolidation, and as we are not aware of any CRS consolidation theory incorporating secondary consolidation, the third issue is not addressed in this reply.

The suggestion that the use of a higher pore pressure ratio (exceeding 0-15) does not necessarily lead to poor results agrees with our experience. Tests MB-0085 and MC-0063 (Fig. 14) provide two examples, and Fig. 16 provides further examples. In this regard, we were pleased to see that the data in Table 4 further support our findings that the pore pressure ratio is generally below or around 0.15 for tests with $\beta$ values below $0 \cdot 1$.

There is certainly more than one method for selecting the test rate. The thrust of the discussion on pore pressure ratio in the Paper was that this ratio was a poor universal indicator. There is no theoretical justification for the use of this ratio, and the recommended value appeared to vary with the type of clay from which the recommendations were derived (Table 3). However, the normalized strain rate $\beta$ provides a unifying foundation for a wide range of clays. An approach based on $\beta$ is most useful in two situ- ations. The first is one where few data exist for the clay tested. The second is one where there is no companion incremental loading (oedometer) test. In such cases as the Rio de Janeiro soft clay where an extensive body of test data is available, it is possible that other, empirically-based criteria may provide better guidance than that based on $\beta$.

We agree that it is equally possible that tests using $\beta$ values exceeding 0.1 can still produce acceptable results. The value of $0 \cdot 1$ is simply the upper bound where our approximate solution, on which the interpretation method was based, is known to be valid. Furthermore, our experience suggest that a test with a $\beta$ value below $0 \cdot 1$ is more likely to produce valid results than one with a $\beta$ value above $0 \cdot 1$. This is also supported by the Writers' data as test CRS8 (the only test reported with a $\beta$ value below $0 \cdot 1$ ) appeared to produce the best agreement between the CRS and the IL tests (Fig. 16).

The discussion of which test achieved the best agreement inevitably raised a related and, in our experience, often overlooked issue of judging the quality of test results. The Paper presented an approach whereby the quality of the test results can be judged by comparison of the compression curves and $C_{v}$ values derived from different parts of the specimen. Good agreement in this case provides convincing proof of a good test.

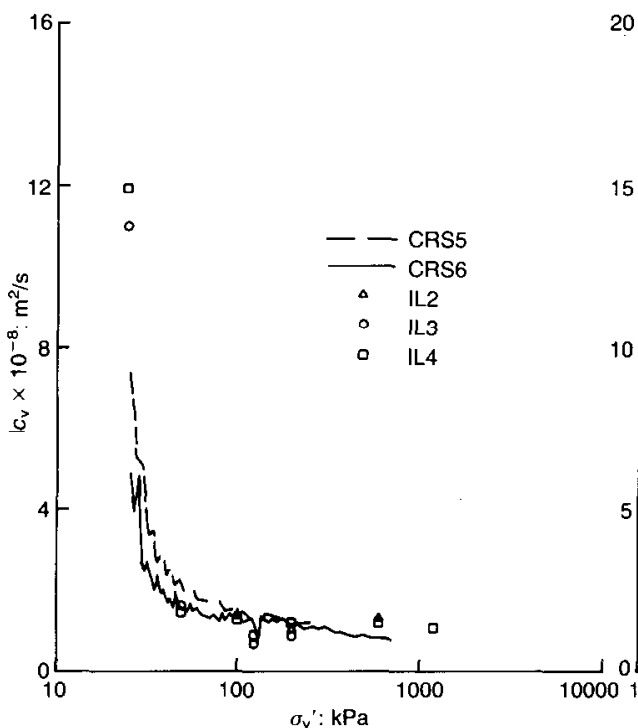

(a)

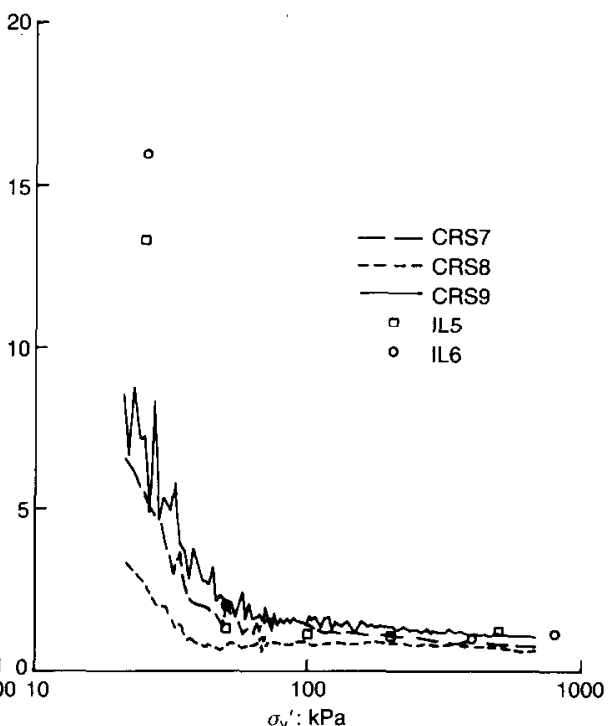

(b)

Fig. 17. Variation of coefficient of consolidation with effective stress for CRS and incremental loading tests in Rio de Janeiro soft clay: (a) depth 3.0-3.5 m; (b) depth 5.0-5.5 m 


\section{REFERENCES}

Almeida, M. S. S. \& Ferreira, C. A. M. (1993). Field, in situ and laboratory consolidation parameters of a very soft clay. In Predictive soil mechanics, pp. 73-93. London: Thomas Telford.

Almeida, M. S. S., Martins, I. S. M. \& Carvalho, S. R. L. (1995). Constant rate of strain consolidation on very soft clays. Proceedings of international symposium on compression and consolidation of clayey soils, Hiroshima. Rotterdam: Balkema.

Carvalho, S. R. L., Almeida, M. S. S. \& Martins, I. S. M. (1993). A method to evaluate the velocity of constant rate of strain consolidation tests (in Portuguese). Solos e Rochas 16, No. 3, Oct., 185-196.

Lacerda, W. A., Costa-Filho, L. M., Coutinho, R. C. \& Duarte, E. R. (1977). Consolidation characteristics of Rio de Janeiro soft clay. Proceedings of conference on geotechnical aspects of soft clay, pp. 231-244. Bangkok.

Ortigão, J. A. R. \& Collet, H. B. (1987) Errors caused by friction in field vane testing. Proceedings of symposium on laboratory and field vane shear strength testing, pp. 104-116. STP 1014. Philadelphia: American Society for Testing and Materials. 